\title{
Pullout strength behaviour of self-compacted concrete in aggressive solutions
}

\author{
Maha Sabhan ${ }^{a}$ and Adnan Al-Sibahy ${ }^{a} *$ \\ ${ }^{a}$ Civil Engineering Department, College of Engineering, The University of Al-Qadisiyah, Iraq
}

\begin{tabular}{l} 
A R T I C L E I N F O \\
\hline Article history: \\
Received 18 November 2019 \\
Received in revised form 22 December 2019 \\
Accepted 30 December 2019 \\
\hline Keywords: \\
Corrosion \\
Epoxy coated \\
Pullout test
\end{tabular}

\begin{abstract}
A B S T R A C T
The aim of this study was to investigate the pullout strength behaviour of self-compacted concrete under corrosion conditions. Block samples with two configurations were formulated. A total number of twelve block samples in addition to 24 cubes were tested. The hardened concrete samples were either cured in tap water or exposed to salt solution. A suitable epoxy was used for coating part of the formulated samples. The preliminary mechanical properties and the rate of corrosion were firstly measured, the pullout was then carried out. A comparison was also made with the relevant code of practice. The results obtained showed that both compressive strength and density features exhibited a notable increase at an early age when the samples are exposed to salt solution. The adverse effect of such curing condition appeared at the later ages when the corrosion rate became more intensive. The highest decrease in the value of pullout strength was observed for the reinforced concrete block samples containing epoxy coating reaching to $44.5 \%$ less than those cured in tap water.
\end{abstract}

\section{Introduction}

It is well known that the steel bars can effectively use in reinforcing the plain concrete to increase its resistance to tension stresses. However, under the conditions of rust and corrosion, maintaining such ability of steel bars is a real challenge for the construction engineers. The rust and corrosion phenomena usually appear at the moist environments and presence of oxygen in addition to salts in the soil or groundwater [1,2]. Consequently, the designed age of the reinforced concrete structures will be affected.

The adverse effect of the corrosion of reinforced steel bars was the main concern for many of the published research works [3-6]. Most of them focused on the ways of protection of the reinforced steel bars from the impact of environmental conditions. It was noted that the coated method can be effectively used in reducing the effect of corrosion. The coating technique mainly depends upon a buffer layer which works as a thin film over the outer surface of the reinforced steel bars [7].

In general, corrosion of minerals is a result of the formation of what so called rust cell. This cell allows for transition of electrons from the anode pole to the cathode pole via an electronic solution [8]. In case of reinforced concrete, the water filling the inner pores of the concrete is the electronic solution responsible for the transmission of electrons released from the oxidation of the steel bars. The aforementioned transmission solution is usually saturated with a high concentration of calcium, potassium and sodium hydroxides resulting from the processing of cement hydration. It was noted that the presence of the basal environment helps to form a protective layer that protects the steel bars from corrosion. In the structural

* Corresponding author.

E-mail address: Adnan.alsibahy@qu.edu.iq (Adnan Al-Sibahy ) 
applications, the bond strength is a function for the integrity of the reinforced concrete composition and usually defined as the force that resists the separation of mortar and concrete from reinforcing steel [9]. The interaction between the reinforced steel bars and the surrounding concrete in addition to the nature of cohesion are the basis of the idea for any structural design $[1,9]$. Previous studies $[10,11]$ pointed out that the critical bond stress developed between the concrete and reinforced steel is revealed throughout applying loading parallel to the direction of steel bars. Such behaviour can be evaluated using a pull-out test which is indicative of a static strength property of the reinforced concrete composition.

Recently, many research works have been published regarding the corrosion of reinforced concrete structures. However, no available research was conducted to investigate the pullout strength behaviour of the selfcompacted concrete (SCC) elements exposed to aggressive environments similar to those found in the soil and groundwater of the southern parts of Iraq. In this paper, the bond strength of SCC samples was experimentally evaluated under the conditions of curing in water and exposed to aggressive salt solution. The effect of using epoxy coated was also investigated. A comparison with the expression proposed by relevant codes of practice was then made.

\section{Experimental Work}

\subsection{Materials used}

In order to get the desired objectives of this study, a high performance selfcompacted concrete mixes were produced using ordinary Portland cement complying with the EN BS 197-1 [12]. Natural sand and crushed gravel were used as fine and coarse aggregates. They have maximum particle sizes of $4.75 \mathrm{~mm}$ and $10 \mathrm{~mm}$, respectively. The corresponding sulfate contents were $0.126 \%$ and $0.082 \%$, respectively. Both of limestone powder and Caplast Super-R were used as a filler and superplasticizer admixture, respectively. Deformed steel bars with diameters of $\varnothing 12.5 \mathrm{~mm}$ and $\varnothing 25$ $\mathrm{mm}$ were adopted in formulating the samples of the block. They have ultimate and yield tensile strength of $660 \mathrm{MPa}$ and $415 \mathrm{MPa}$, respectively. An epoxy H. Polypoxy CR type was used as a corrosion inhibitor for the reinforced steel bars. It is a solvent-free high build epoxy resin that provides a chemical resistant for both concrete and steel bars. It was supplied separately as two parts, namely resin and hardener.

\subsection{Selection of the concrete mix}

Following the procedure described for the common mix design method [13], an optimal concrete mix was designed in order to obtain a selfcompacted concrete mixture that possesses high flowability and compressive strength in the range of $35 \mathrm{MPa}$. This in turn gives a concrete mixture with a mix proportion of 1:1.8:2 (cement: sand: grave) by weight. The cement content and W/C ratio of the former mixture were $400 \mathrm{~kg} / \mathrm{m}^{3}$ and of 0.58 , respectively. The dosage of the super-plasticizer was $1 \%$ by weight of cement. For the assessment purposes, the flowability aspect was measured using slump, flow, J-ring, V-funnel, and L-box test methods. The results obtained for the flowability and compressive strength features are shown in Table 1.

Table 1. Flowability and compressive strength values of the selected SCC

\begin{tabular}{clllll}
\hline $\begin{array}{c}\text { Slump } \\
(\mathbf{m m})\end{array}$ & $\begin{array}{l}\text { Slump- } \\
\text { flow } \\
(\mathbf{m m})\end{array}$ & $\begin{array}{l}\text { L- } \\
\text { test } \\
\mathbf{c m}\end{array}$ & $\begin{array}{l}\text { V- } \\
\text { funnel } \\
\text { second }\end{array}$ & $\begin{array}{l}\text { j-ring } \\
\text { test } \\
\mathbf{c m}\end{array}$ & $\begin{array}{l}\text { Compressive strength } \\
\text { MPa at 28 days }\end{array}$ \\
\hline 265 & 578 & 5.5 & 3 & 10 & 36.8 \\
\hline
\end{tabular}

\subsection{Preparation of salt solution}

A composite solution of chloride and sulfate salts was prepared as an attack environment for the reinforced concrete samples. The concentrations of these salts are similar to those available in the soil and underground water of the southern parts of Iraq. The raw compositions of the former salts were $\mathrm{NaCl}, \mathrm{MgSO}_{4} \cdot 7 \mathrm{H}_{2} \mathrm{O}$, and $\mathrm{CaCl}_{2} \cdot 2 \mathrm{H}_{2} \mathrm{O}$, as shown in Fig. 1. The concentration of the former salts are $45.1 \mathrm{~g} / 1,17.9 \mathrm{~g} / \mathrm{l}$, and $5.5 \mathrm{~g} / \mathrm{l}$, respectively.

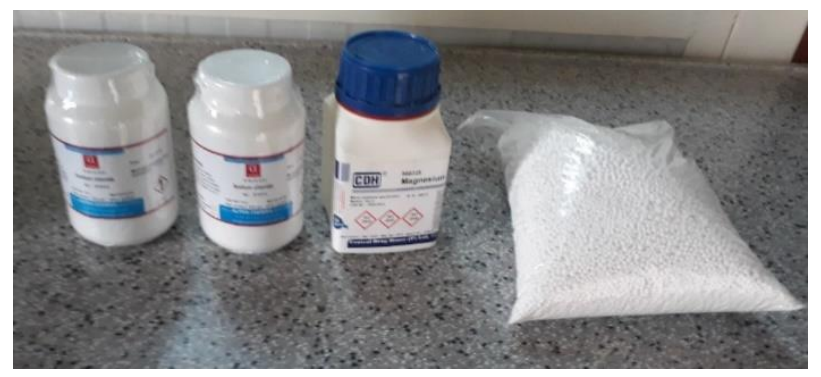

Figure 1. Types of salts used in the preparation of aggressive solutions

\subsection{Preparation of moulds, mixing, casting and curing operations}

Play-wood moulds were designed for the purpose of casting the reinforced concrete blocks. Two configurations of wooden moulds were fabricated. The first has a dimensions of $200 \times 120 \times 120 \mathrm{~mm}(1 \times \mathrm{w} \times \mathrm{h})$ [14] which was designed for running the pullout test for the concrete blocks reinforced with the steel bar of $\varnothing 12.5 \mathrm{~mm}$. Whilst, the second was designed with dimensions of $375 \times 250 \times 250 \mathrm{~mm}(1 \times w \times$ h) [14] to suit the pullout test for the concrete blocks reinforced with the steel bar of $\varnothing 25 \mathrm{~mm}$, as shown in Fig. 2., while Fig. 3. shows the final composition for the beam and block moulds with their steel reinforcements.
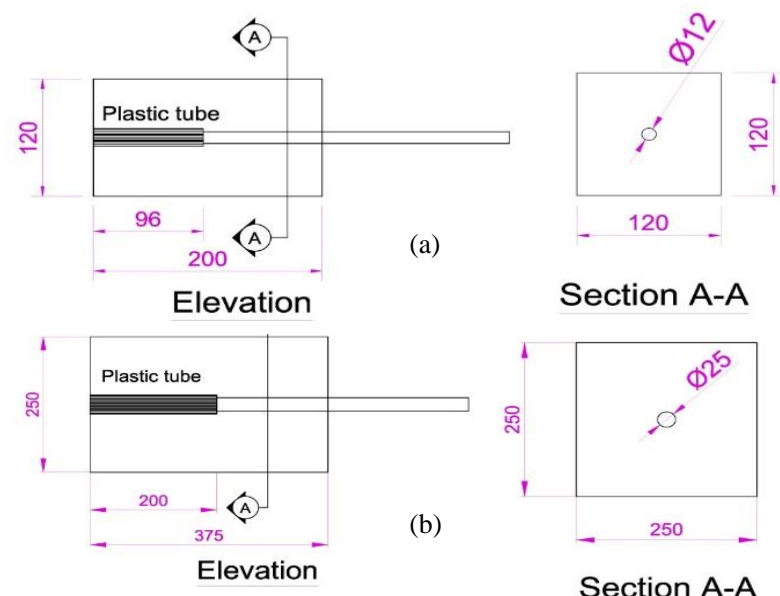

Section A-A

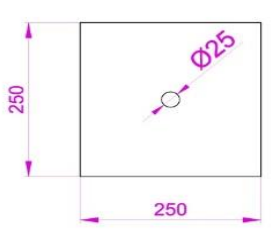

Section A-A

Figure 2. Details of moulds: (a) blocks reinforced with $\emptyset 12.5 \mathrm{~mm}$; (b) blocks reinforced with $\emptyset 25 \mathrm{~mm}$ 


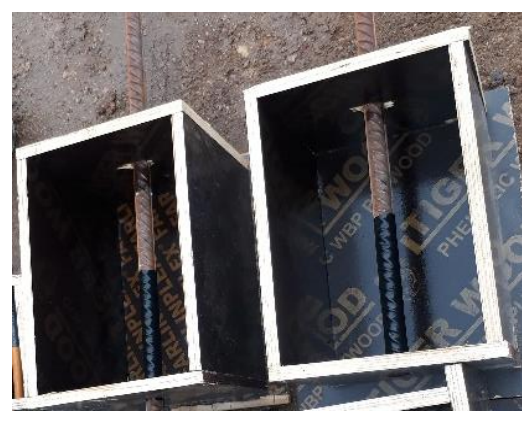

Figure 3. The final composition of the block moulds with their steel reinforcements

The mixing, casting and curing operations were carried out in accordance with BS EN12390-2 [15]. Cubes samples were also cast to measure the compressive strength and density feature at different ages. Following the methodology adopted in this study, all of the concrete samples were firstly cured in water for 7 days. After that, the samples intended to be exposed to aggressive environment were only cured in salt solution for a period of 6 months. The corrosion phenomenon of the reinforced block samples was computed under the conditions of cured in water, exposed to a salt solution with an without epoxy coated after a period of 6 months of exposure. After that period, the pullout test was then performed.

\subsection{Corrosion measurements}

The technique of electrical current passing through a specified length of steel bar was used to measure the amount of corrosion. A voltmeter device was used to supply a constant voltage (220 voltage), then the values of electrical current released were recorded, as shown in Fig. 4. In such a case, the corrosion of the steel bar is normally accounted for in the form of an affected cross-sectional area, as described in Eq.1.

\section{$\mathrm{A}=\left(\int \mathrm{L}\right) / \mathrm{R}$}

where $\mathrm{A}$ is the affected cross-sectional area of steel bar due to the corrosion in $\mathrm{mm} 2, \int$ is the quality resistance in Omm which is equal to $7.36^{*} 10^{-8}, \mathrm{~L}$ is the length of steel bar in $\mathrm{mm}$ and $\mathrm{R}$ is the electrical resistance of the steel bar in Omm per mm.

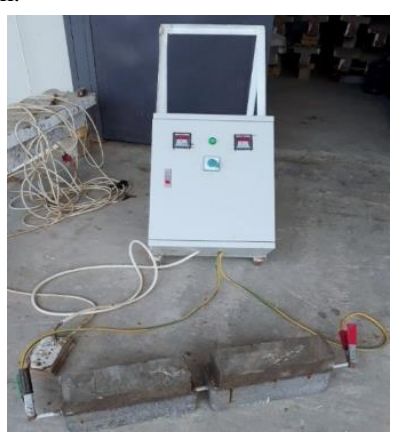

Figure4. Corrosion test method

\section{Results and discussion}

\subsection{Preliminary mechanical properties}

The results obtained for the mechanical properties of the hardened concrete samples are shown in Figs. 5 and 6. It can be seen that the compressive strength of the plain concrete samples tends to increase with the increase of curing age. This is due to the progressing in the hydration of cement paste with time. At early ages, the concrete samples cured in salt solution showed higher compressive strength than those cured in tap water. This behaviour can be explained by increasing the volume of solid hydration products in the present of salt solution. The latter prompts formation of calcium trisulfoaluminate which so called ettringite. At the later curing ages, the former product being unstable and convert to calcium monosulfoaluminate $[8,9]$. This in turn means decreasing the value of compressive strength and the effect of salt being appear in terms of disintegration of the concrete.

Similar behaviour was also noted for the values of densities of hardened concrete samples to that observed for the compressive strength. This supports the justified previously mentioned for explaining the behaviour of compressive strength with time of curing. The percentage increase in the value of density at 7 days for the concrete samples cured in salt solution was about $5 \%$ compared with those cured in water. On the other hand, the density value showed a reduction at 180 days age with a percentage decrease reaching to $2 \%$. Conversely, a continues increase in the value of density with time was observed for the concrete samples cured in water. This was expected as the empty capillary pores are filled with the solid hydration products.

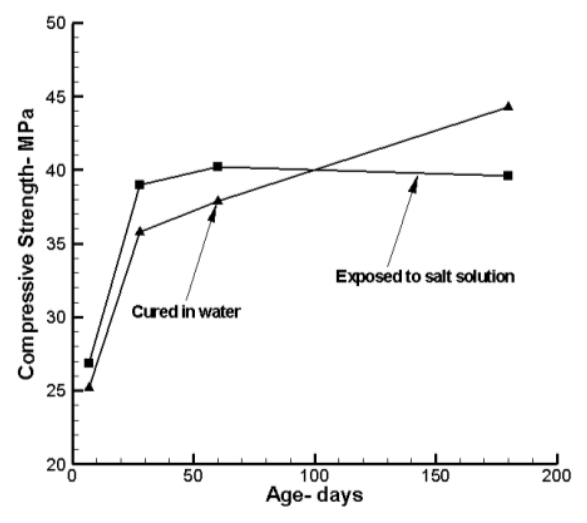

Figure 5. The values of compressive strengths at different curing conditions

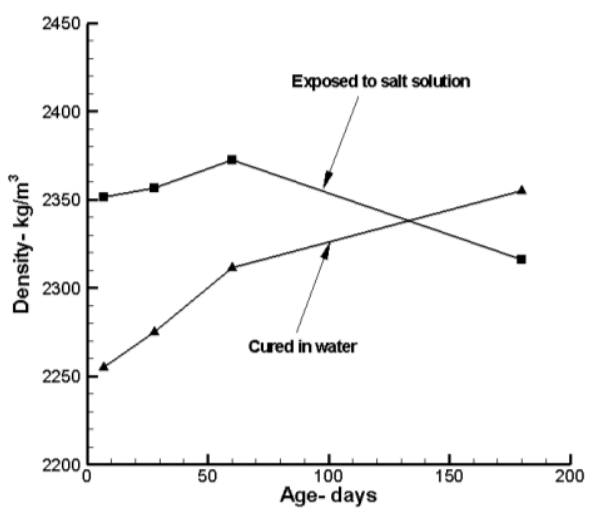

Figure 6. The values of concrete densities at different curing conditions

\subsection{Corrosion behaviour of the reinforced concrete elements}

The results obtained for the corrosion behaviour of the reinforced block samples at different curing conditions in terms of the value of current passing and the calculated volume of the embedded steel bar are presented in Table 2 and Figs 7 and 8. 
Table 2. The current values for the reinforced block samples

\begin{tabular}{|c|c|c|c|c|c|c|c|c|c|c|}
\hline \multirow{2}{*}{ Type of element } & \multirow{2}{*}{ Type of curing } & \multicolumn{9}{|c|}{ Current value (Ampere) at different curing ages } \\
\hline & & 7 days & 14 days & 28 days & 1 month & 2 months & 3 months & 4 months & 5 months & 6 months \\
\hline Block samples & water & 190 & 189.26 & 185.93 & 181.1 & 179 & 175 & 164 & 157 & 155 \\
\hline reinforced with steel $\mathrm{t}$ & Salt with epoxy coated & 190 & 190 & 189.4 & 188 & 188 & 186 & 184 & 182 & 182 \\
\hline of $\varnothing 25 \mathrm{~mm}$ & Salt without epoxy & 188.99 & 188.7 & 186 & 175.1 & 161 & 161 & 144 & 141.5 & 139.9 \\
\hline Block samples & water & 85 & 85 & 79 & 99 & 110 & 105 & 114 & 102 & 78 \\
\hline reinforced with steel & Salt with epoxy coated & 83.5 & 86 & 72 & 102 & 116 & 91 & 72 & 119 & 100 \\
\hline bar of $12.5 \mathrm{~mm}$ & Salt without epoxy & 79.9 & 77.9 & 70.7 & 95.5 & 93 & 114 & 121 & 44 & 90 \\
\hline
\end{tabular}

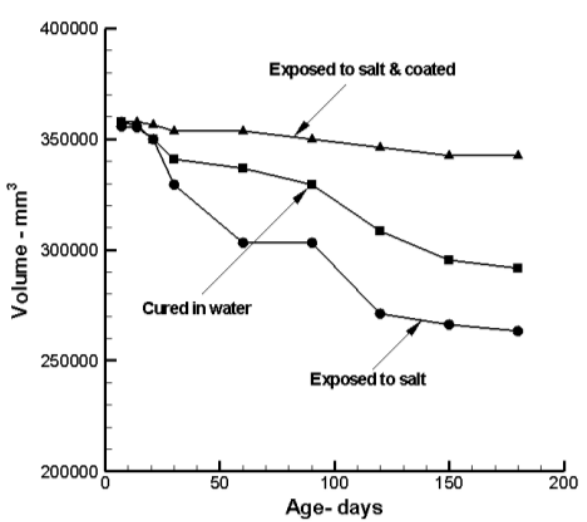

Figure 7. The volume of the embedded steel bars of $\emptyset 25 \mathrm{~mm}$ in the block samples at different curing conditions

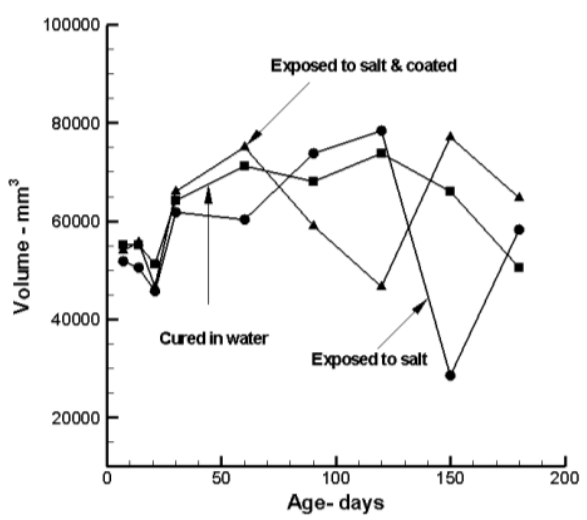

Figure 8. The volume of the embedded steel bars of $\emptyset 12.5 \mathrm{~mm}$ in the block samples at different curing conditions

It can be seen that the volume of the embedded steel bars tends to decrease with the increase in the time of curing. So, for the purpose of durability evaluation, the behaviour of reinforced concrete element usually monitored for a long-term (at least for a six months) [16]. This is consistent with the results obtained for the plain concrete samples in which the adverse effect of sulfate attack appeared at the later ages. In general, the decrease in the volume of steel bar depends mainly on the nature of curing conditions. It was minimal for the block samples incorporated epoxy coated. Whilst a notable decrease in the volume of steel bars was noted for the case of curing in tap water. On the other hand, the highest volume change was observed for the samples exposed to salt solution. This is indicative for the corrosion of the reinforced steel bars and can be explained by the reaction of chloride salt with the outer surface of steel bar [8]. Existence of the salt solution prompts the aforementioned reaction throughout disintegration of the concrete cover and increasing its porosity [9]. On this basis, a direct contact can be achieved over the available surface of steel bar.
It is important to note that the value of electrical current passing through the steel bar for constant voltages exhibited a constant decrease over time, as shown in Tables 2. This represents the concept of the electrochemical process of corrosion phenomenon which results in a volume change of the reinforced steel bars.

The percentage decrease in the volume of steel bars of $\varnothing 25 \mathrm{~mm}$ used in reinforcing the block samples at 180 days compared with those cured at 7 days for the cases of curing in water, cured in salt solution and cured in salt solution with epoxy coated were $18,27 \%$ and $5 \%$, respectively. Whilst, the results for the steel bars of $\emptyset 12.5 \mathrm{~mm}$ were unrealistic.

\subsection{Pullout behaviour}

Figs. 9 and 10 illustrate the results obtained for the pullout behavour of the reinforced concrete blocks. Except for the ultimate values of pull-out force and slipping, both of these figures showed identical bond-slip curves for all of the tested samples. This was expected as a similar type and composition of concrete was used in this study.

It was clearly shown that the ultimate pull-out force increases with the increase of the bar diameters. This mainly due to higher shear resistance propagated over the bar perimeter. Such resistance is also dependent upon the geometry of the rib. The percentage increases in the values of ultimate pull-out forces for the steel bars of $\varnothing 25 \mathrm{~mm}$ in respect to those of $\varnothing 12.5$ $\mathrm{mm}$ for the block samples cured in water, exposed to salt solution and epoxy coated were $73 \%, 73$ and 78 , respectively.

Similarly, the values of displacements were consistent with their corresponding values of ultimate pull-out forces. Consequently, the highest displacement value was recorded for the steel bar of the larger diameter. This means a higher potential of pull-out force is needed to cause the ultimate slipping and failure for the block sample.

The role of curing conditions was obvious in the results obtained. For the same diameter of steel bar, the bock samples cured in water show the highest pullout force and slipping values compared with those cured in other conditions. A notable decrease in the values of pullout force and slipping was noted for the block samples exposed to salt solution. The percentages decrease in the values of ultimate pull-out forces for the steel bars of $\varnothing 25 \mathrm{~mm}$ and $\varnothing 12.5 \mathrm{~mm}$ compared with those cured in tap water were $21 \%$ and $22 \%$, respectively. The corresponding percentages decrease for the slipping values were $5.7 \%$ and $14.4 \%$, respectively. The reason for this reduction may be related to impairment of the bond between the concrete and steel bar resulting from the corrosion phenomenon. Such an attitude tends to reduce the cross-sectional area of the bar as early as mentioned. Consequently, many voids are formed in the interaction zone between the concrete and steel bar associated with the weakness of the bars itself [17].

The worst scenario was observed for the case of reinforced block samples incorporated epoxy coated. The latter case an indicator of the adverse effect of epoxy on reducing both of the ultimate pull-out force and slipping value. The percentages decrease in the values of ultimate pull-out forces for block samples reinforced with steel bars of Ø12.5 mm and Ø25 mm containing epoxy coated compared with those cured in water were $44 \%$ and $31 \%$, 
respectively. The corresponding percentages decrease in the slipping values were $19.5 \%$ and $22.4 \%$, respectively. Such behaviour can be explained by forming a film around the steel bars which considerably tends to reduce the mechanical friction resulting at both surfaces of concrete and steel bars. The latter friction is the major source of bond strength. Based upon the above results two opposite roles were noted for the epoxy coated: preventing the corrosion to be occurred and inducing less bond to the reinforced concrete composition.

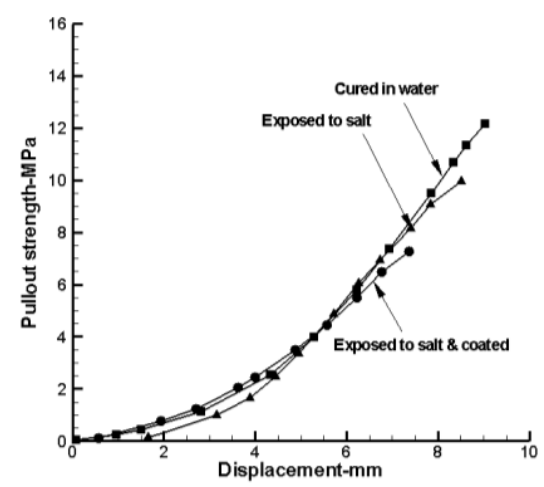

Figure 9. Pullout strength-displacement relationship for block samples reinforced with steel bar of $\emptyset 12.5 \mathrm{~mm}$

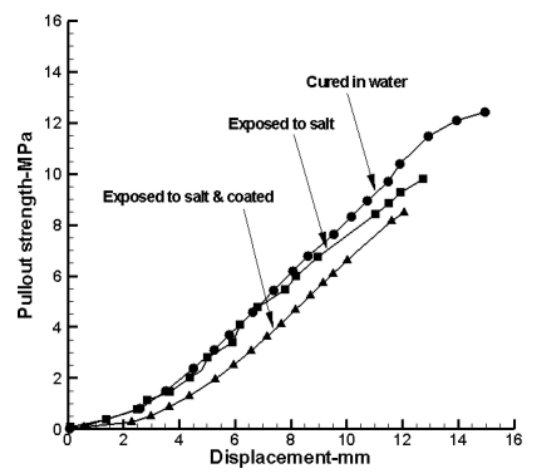

Figure 10. Pullout strength-displacement relationship for block samples reinforced with steel bar of $\emptyset 25 \mathrm{~mm}$

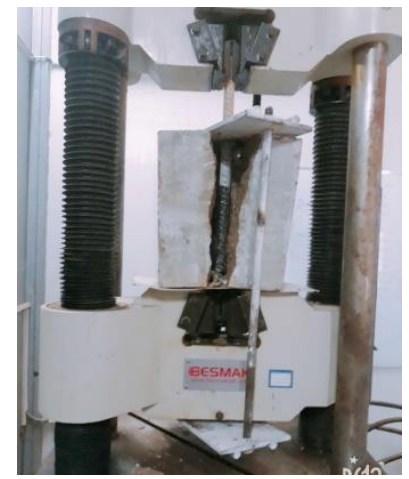

(a)

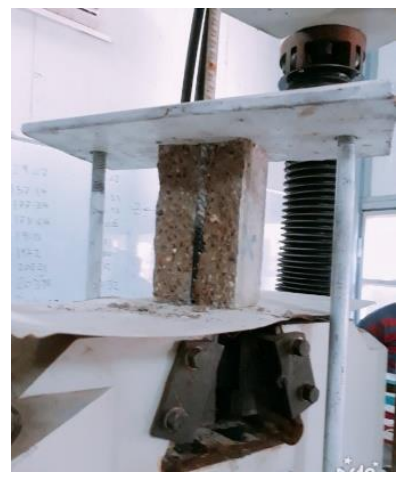

(b)
Figure 11. The failure modes of the block samples: (a) extension of the slipping cracks (b) completely failure
In terms of the failure modes, the cracks appear firstly at the top surface of the samples underneath the holding plate associated with slipping of the steel bar. When the pullout load increases, the cracks extend to the sample height, as shown in Fig. 11-a. Completely splitting failure mode is then took place at the point of ultimate load, as shown in Fig. 11.b.

\subsection{Compassion with the code of practice}

In order to explore the structural applications of the experimental results obtained in this study a comparison was made with the relevant code of practice. In this regards, CEB-FIP [18] proposed Eq. 2 to calculate the bond strength in term of shear resistance of a specified steel bar embedded within a concrete composition, as follows:

$\tau_{\text {bu,split }}=\eta_{2} 6.5\left(\frac{\mathrm{f}_{\mathrm{cm}}}{25}\right)^{0.25}\left(\frac{25}{\varnothing}\right)^{0.2}\left[\left(\frac{\mathrm{C}_{\mathrm{min}}}{\emptyset}\right)^{0.33}\left(\frac{\mathrm{C}_{\mathrm{max}}}{\varnothing}\right)^{0.1}+\mathrm{k}_{\mathrm{m}} \mathrm{k}_{\mathrm{tr}}\right]$

where $\eta_{2}$ is a parameter representing the bond condition and taken as 1.0 for good bond and 0.7 for all other bond conditions, $\mathrm{f}_{\mathrm{cm}}$ is the cylinder concrete compressive strength in $\mathrm{MPa}, \varnothing$ is the diameter of the anchored bar in $\mathrm{mm}, \mathrm{C}_{\min }$ is the min. $\mathrm{Cx}, \mathrm{Cy}$ and $\mathrm{C}_{\max }$ is the max $\mathrm{Cx}, \mathrm{Cy}$ taken based on the Fig. 12, $\mathrm{k}_{\mathrm{m}}$ represents the efficiency of confinement from transverse reinforcement which has a value of 12 where bars are confined inside a bend of links passing around the bar of at least $90^{\circ}$ and $\mathrm{k}_{\mathrm{tr}}$ is calculated using Eq. 3.

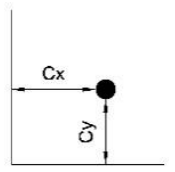

Figure 12. Shows the spacing and cover of the straight bar; $\mathrm{Cx}$ and Cy

$$
k_{t r}=\frac{\eta_{1} A_{s t}}{\eta_{b ø s_{t}}} \leq 0.05
$$

where $\eta_{1}$ is the number of legs of confining reinforcement crossing a potential splitting failure surface at a section, $A_{\text {st }}$ is the cross-sectional area of one leg of confining bar in $\mathrm{mm}^{2}, \mathrm{n}_{\mathrm{b}}$ is the number of anchored bars or pairs of lapped bars in the potential splitting surface and $S_{t}$ is the longitudinal spacing of confining reinforcement in $\mathrm{mm}$.

Applying Eq. 2., taken into consideration $\eta_{2}$ value is 1.0 for samples cured in water and 0.7 for those epoxy coated. On the other hand, the CEB-FIP [18] suggested the value of $\eta_{2}$ for the corroded reinforcement is 0.4 for the non-confinement elements. The calculated bond strength with their corresponding measured values are illustrated in Table 3.

Table 3. The measured and calculated values of bond strength $(\tau)$

\begin{tabular}{lllll}
\hline Type of curing & \multicolumn{2}{l}{$\begin{array}{l}\text { Experimentally measured } \\
\text { values of }(\boldsymbol{\tau}) \text { in } \mathbf{M P a}\end{array}$} & \multicolumn{2}{c}{$\begin{array}{l}\text { Calculated values of }(\boldsymbol{\tau}) \\
\text { using Eq.2 in } \mathbf{M P a}\end{array}$} \\
\hline & $\varnothing 25$ & $\varnothing 12.5$ & $\varnothing 25$ & $\varnothing 12.5$ \\
Cured in water & 12.42 & 12.16 & 14.00 & 16.00 \\
Exposed to salts & 9.79 & 9.95 & 5.64 & 6.54 \\
Epoxy coated & 8.47 & 7.36 & 9.88 & 11.45 \\
\hline
\end{tabular}

It can be seen that the highest differences between the measured and calculated results of the bond strength were noted for the block samples. This may be due to the nature of pullout technique which represents a direct test method. On this basis, Eq. 2 needs to be amended in order to fit the experimental measurements obtained in this study. It was found that the suggested values of $\left(\eta_{2}\right)$ are as per in Table 4 . 
Table 4. The suggested values of $\eta_{2}$

\begin{tabular}{lll}
\hline Type of curing & $\eta_{2}$ values & \\
& $\varnothing 25$ & $\emptyset 12.5$ \\
\hline Cured in water & 0.88 & 0.76 \\
Exposed to salts & 0.60 & 0.70 \\
Epoxy coated & 0.64 & 0.48 \\
\hline
\end{tabular}

\section{Conclusions}

This study was conducted in order to investigate the bond strength behaviour of reinforced self-compacted concrete elements exposed to different curing conditions. The main findings of this study can be summarized as follows:

- The compressive strength and density values showed a notable increase at the early ages when the concrete samples exposed to aggressive solutions. However, a contrast behaviour was noted at the later ages (i.e. beyond 120 days) where a decomposition for the main components of cement paste took place.

- The rate of corrosion increases with an increase in the time of exposure to the salt solution. Such behaviour was only noted for the uncoated steel bars, whilst the epoxy coated prevent the occurrence of the corrosion phenomenon.

- The pull-out strength value adversely affected when the reinforced steel bar of the concrete block samples exhibited a notable corrosion at the external surfaces due to exposure to the salt solution. The percentage decreases in such a case compared with that of cured in tap water were $17.7 \%$ and $21 \%$ for the steel bars of $\varnothing 12.5 \mathrm{~mm}$ and $\varnothing 25 \mathrm{~mm}$, respectively.

- The highest decrease in the value of pull-out strength was observed for the reinforced concrete blocks containing an agent of epoxy coating. This was mainly due to the role of such agent in reducing the adhesion between the steel bars and the surround concrete. The percentage decreases in the former reinforced block samples when compared with those of free coating agent and cured in tap water were $44.5 \%$ and $31.2 \%$ for the steel bars of $\varnothing 12.5 \mathrm{~mm}$ and $\varnothing 25 \mathrm{~mm}$, respectively.

\section{REFERENCES}

[1] Mindess S, Young JF, Darwin D. Concrete. New Jersy: Prentice-Hall; 2002.
[2] Wang K, Jansen D, Shah S, Karr A. Permeability study of cracked concrete. Cement Concrete Researches 1997;27:381-93.

[3] A. Hassan, K. Hossain, M. Lachemi, Corrosion resistance of selfconsolidating concrete in full-scale reinforced beams, Cement and Concrete Composites, Volume 31, Issue 1, 2009, (29-38).

[4] Yanhui Cao, et. al., Multifunctional inhibition based on layered double hydroxides to comprehensively control corrosion of carbon steel in concrete, Corrosion Science, Volume 126, 2017, (166-179).

[5] Marco Manera, ystein Vennesland, Luca Bertolini, Chloride threshold for rebar corrosion in concrete with addition of silica fume, Corrosion Science, Volume 50, Issue 2, 2008, (554-560).

[6] Zhitao Chen, En-Hua Yang, Microstructural investigation of steel corrosion in strain hardening cementitious composite (SHCC), Construction and Building Materials, Volume 211, 2019, (185-198).

[7] Yingang Du, Martin Cullen, Cankang Li, Structural performance of RC beams under simultaneous loading and reinforcement corrosion, Construction and Building Materials, Volume 38, J 2013, ( 472-481).

[8] P. Kumar Mehta, Paulo J. M. Monteiro, Concrete, Microstructure, Properties, and Materials, 3th edition, 2006.

[9] Neville A (2000) Properties of Concrete, 3th edn. Pearson Education Limited, Edinburgh, UK.

[10] Masoud Ahmadi, et. al., New empirical approach for determining nominal shear capacity of steel fiber reinforced concrete beams, Construction and Building Materials, Volume 234, 20 2020, Article 117293.

[11] Sahith Gali, Kolluru V. L. Subramaniam, Cohesive stress transfer and shear capacity enhancements in hybrid steel and macro-polypropylene fiber reinforced concrete, Theoretical and Applied Fracture Mechanics, Volume 103, October 2019, Article 102250.

[12] EN BS 197-1. Cement, Part 1: Compositions, specification and conformity criteria for common cements. British Standards; 2000.

[13] Paratibha Aggarwal, et. al., Self-Compacting Concrete- Procedure for Mix Design, Leonardo Electronic Journal of Practices and Technologies, Issue 12, 2008(15-24).

[14] E. P. Carvalho, E. G. Ferreira, J. C. da Cunha, C. de S. Rodrigues, and N. da S. Maia, Experimental investigation of steel-concrete bond for thin reinforcing bars, Lat. Am. J. Solids Struct., vol. 14, no. 11, pp. 1932-1951, 2017.

[15] BS EN 12390-2. Making and curing specimens for strength test. British Standards, 2009.

[16] Subbiah Karthick, et. al., Reliability and long-term evaluation of GO$\mathrm{MnO} 2$ nano material as a newer corrosion monitoring sensor for reinforced concrete structures,

Cement and Concrete Composites, Volume 100, 2019 ( 74-84).

[17] Xianming Shi, et. al., Durability of steel reinforced concrete in chloride environments: An overview, Construction and Building Materials 30 (2012) 125-138.

[18] CEB-FIP, Model Code 2010, International Federation for Structural Concrete (fib), 2010. 